University of Rhode Island

DigitalCommons@URI

Open Access Master's Theses

2001

\title{
LA CONCEPTUALIZACIÓN DE LA CULTURA EN LA OBRA DE SARMIENTO Y SUS IMPLICACIONES POLÍTICAS PARA LA FORMACIÓN DE UNA IDENTIDAD CULTURAL ARGENTINA
}

Marta Belen Rodriguez Galan

University fo Rhode Island

Follow this and additional works at: https://digitalcommons.uri.edu/theses

\section{Recommended Citation}

Rodriguez Galan, Marta Belen, "LA CONCEPTUALIZACIÓN DE LA CULTURA EN LA OBRA DE SARMIENTO Y SUS IMPLICACIONES POLÍTICAS PARA LA FORMACIÓN DE UNA IDENTIDAD CULTURAL ARGENTINA" (2001). Open Access Master's Theses. Paper 1822.

https://digitalcommons.uri.edu/theses/1822

This Thesis is brought to you for free and open access by DigitalCommons@URI. It has been accepted for inclusion in Open Access Master's Theses by an authorized administrator of DigitalCommons@URI. For more information, please contact digitalcommons-group@uri.edu. 
LA CONCEPTUALIZACION DE LA CULTURA EN LA OBRA DE

SARMIENTO Y SUS IMPLICACIONES POLITICAS PARA LA FORMACION DE UNA IDENTIDAD CULTURAL ARGENTINA

BY

MARTA BELEN RODRIGUEZ GALAN

THESIS SUBMITTED IN PARTIAL FULFILLMENT OF THE

REQUTREMENTS FOR THE DEGREE OF

MASTER OF ARTS

IN

SPANISH

UNIVERSITY OF RHODE ISLAND

2001 


\section{SINOPSIS}

El propósito fundamental de este trabajo es discutir cómo Sarmiento conceptualiza la cultura y cuáles son las implicaciones prácticas de esa cosmovisión en su política educativa. Como veremos su ideario está muy influido por ideas racionalistas y utilitaristas.

Por medio de fuentes de la erudición histórica y literaria trataremos de explicar las condiciones originales en que fue creada la obra de Sarmiento. También utilizaremos teorías más actuales (Jacques Derrida, Walter Benjamín, Fredric Jameson...) para poner el debate en perspectiva.

Otro de los objetivos de este trabajo es profundizar en el estudio de las ideas de Sarmiento sobre la cultura, rescatando para el estudio crítico algunos de los textos más olvidados, como sus escritos sobre educación y los Viajes. También haremos referencia a otras obras: Facundo y Recuerdos de Provincias fundamentalmente.

En conclusión, podemos decir que dentro del esquema cultural que dibuja Sarmiento, al calificar a las culturas indígenas, africanas, la cultura del gaucho, del hombre de pueblo como bárbaras, les otorga un valor sólo potencial. Ve los beneficios del mestizaje en el mulato, pero su falta de profundización sobre la realidad étnica, le impide poder vislumbrar una síntesis cultural que incorpore otros valores y otros logros culturales distintos de los de Europa o Estados Unidos. Debe reconocerse el gran esfuerzo de Sarmiento por hacer llegar la educación a las masas, sin embargo no resuelve el problema de la identidad argentina. 
Quiero dedicar este trabajo a mi familia. A mis padres Ana Galán y José Rodríguez quienes con su sacrificio, cariño y apoyo han hecho posible que yo obtuviese la educación que ellos no pudieron disfrutar. También dedico este trabajo a mi abuela Anita, en paz descanse, que significa tanto para mí, y a mi hermano Sergio por su gran cariño y amistad. Finalmente se la dedico también a Noelia Martínez porque su amistad de muchos años ha sido y es también esencial. De todos ellos he aprendido lo más importante. 


\section{AGRADECIMIENTOS}

Quiero agradecer a todos mis profesores de la Universidad de Rhode

Island por su calidad humana, su habilidad para transmitir y compartir los muchos conocimientos que poseen y por su ejemplo como profesores:

En primer lugar, quiero expresar mi profunda admiración y agradecimiento al profesor Tomás Morín, director de esta tesina. Sin su sabia orientación y apoyo este proyecto no hubiera sido posible. El profesor Morín me introdujo en el estudio de la literatura y la cultura latinoamericana; con muchísima humildad y comprensión el profesor Morín tiene la habilidad de inspirar al estudiante sea cual sea su grado de experiencia. Mil gracias por todo su trabajo y apoyo.

A la profesora Susana de Los Heros, que me inició en el estudio de la lingüística en una interesantísima clase sobre el Español en América Latina, fundamental para mi preparación como maestra. Gracias por facilitar mi trabajo como maestra y ofrecer consejo. Gracias también por su generosidad y todas sus atenciones.

A Mario Trubiano, mi paisano de Trubia y mentor, quien me ha guiado en el estudio de la literatura peninsular en tres magníficas clases y un estudio independiente sobre el Quijote. El profesor Trubiano, por su confianza en mi capacidad y su apoyo en situaciones en que necesité una ayuda ha sido mi mejor aliado.

Gracias también a Clemente White por todo su trabajo y ayuda en la orientación y elaboración de mi programa de estudios, y por guiarme en el estudio 
de la literatura afrolatina y en especial la poesía de Nicolás Guillén, en la estupenda clase que tomé con él y que tanto disfruté. Gracias por todos sus buenos consejos y gracias por su amistad.

También quiero agradecer la colaboración y amabilidad de los profesores Rosa María Pegueros y Alain Philipp, que han contribuido con su comentario experto a afinar este trabajo. 


\section{INDICE}

Capítulo I: Introducción .............................................. 4

Capítulo II: La utopía sarmentina : civilización y barbarie

2. 1. La génesis de un discurso : civilización vs barbarie.............5-12

2. 2. La civilización como utopía en Sarmiento.....................13-19

2. 3. Civilización e identidad argentina..........................20-25

Capítulo III : La educación como instrumento civilizador...................26-42

Conclusión......................................................................

Bibliografía 


\section{Capítulo I}

\section{Introducción}

Peter Earle ${ }^{1}$ sostiene que el ensayo empieza a ser en Hispanoamérica algo así como la conciencia del hombre sensible con su historia desde la época de Echeverría y Sarmiento.

Efectivamente, en la literatura de Domingo Faustino Sarmiento el desarrollo histórico de una identidad cultural argentina representa un problema recurrente. Cuando en sus escritos Sarmiento elabora un discurso sobre la cultura está asimismo reflexionando sobre el proceso de desarrollo de una cultura y la creación de una identidad nacional.

Cada persona como parte de un grupo dentro de la sociedad brinda una serie de valores que pasan a representar un determinado papel en el funcionamiento de una maquinaria política y social. La identidad cultural, en donde se ven reflejados unos determinados valores, proporciona a los miembros de la sociedad un sentimiento de unidad emotiva y política. Esa identidad cultural tiene un carácter evolutivo. Nos interesa en la presente tesina tratar de identificar los valores culturales que Sarmiento quiere ver representados en la joven nación argentina. Para ello, nos proponemos analizar cómo Sarmiento conceptualiza la cultura y cuáles son los elementos que para él deben formarla.

En la obra de Faustino Sarmiento, intelectual, escritor, educador y político, el debate sobre la cultura es especialmente productivo. Dentro del amplio

\footnotetext{
${ }^{1}$ Earle, $\mathrm{P}$ « El ensayo hispanoamericano como experiencia literaria » El ensayo y la crítica literaria en Iberoamérica ; memoria del XIV congreso del XIV Congreso Internacional de Literatura Iberoamericana. Universidad de Toronto, Toronto, Canadá, 24-28 de agosto de 1969. Edición al cuidado de Kurt L. Levy y Keith Ellis, Universidad de Toronto, 1970.
} 
contexto de su obra examinaremos las proyecciones de su cosmovisión:

esencialmente qué elementos culturales le atraen y quiere implantar o preservar en su país. Por otro lado, también nos interesa ver qué elementos de la cultura le interesa eliminar a Sarmiento. Finalmente discutiremos cuál es el futuro de Argentina si se siguen las implicaciones prácticas de esta visión cultural.

Por muchos años se ha ignorado el análisis de algunos de sus escritos de Sarmiento. A nuestro entender esto ha dado como resultado una carencia de conexiones intertextuales. Otro de los objetivos con esta tesina es rescatar para el estudio crítico algunos de los textos más olvidados, como sus escritos en torno a la educación y los Viajes, de manera que podamos ampliar la comprensión del concepto de cultura que prevalece en la literatura de Faustino Sarmiento.

Por medio de fuentes de la erudición histórica y literaria trataremos de explicar las condiciones originales en que fue creada la obra de Sarmiento. Optamos por este método, puesto que nuestro propósito fundamental es tratar de ver la "razón de ser" de las ideas sarmentinas antes que empezar por juzgarlas. Sin embargo, utilizaremos la teoría más actual en ocasiones para poner también la obra en perspectiva en torno al debate sobre las ideas.

En el capítulo II "La utopía cultural sarmentina: civilización versus barbarie" iniciaremos la discusión ofreciendo una explicación de la génesis y evolución del discurso sobre la civilización. Recurriremos a la obra de distintos filósofos y pensadores (Aristóteles, Condorcet, Rousseau...), también presentaremos una visión crítica de esta idea aludiendo a la teoría sobre la filosofía de la historia de Walter Benjamín y la teoría de la "deconstrucción" de 
Jacques Derrida. Asimismo nos serviremos de otros análisis literarios sobre la obra de Sarmiento como los de Félix Weinberg (1989) y María Rosa Lojo (1992).

En el apartado segundo del capítulo II "La civilización como utopía en Sarmiento", nos acercaremos a la visión cultural de Sarmiento, lo que Frederic Jameson llama el "impulso utópico" del texto. Tomaremos como punto de partida el artículo de María E. S. Cywiner (1989), aunque presentando algunas objeciones a su estudio. Exploraremos cómo define Sarmiento la "civilización" y la relación entre esta conceptualización con las ideas de algunos pensadores modernos. También analizaremos qué entiende Sarmiento por cultura y cuáles son los modelos que le inspiran. Recurriremos como material textural Sarmentino a los Viajes, Recuerdos de Provincia y Facundo.

Para terminar con el capítulo II, veremos la relación de la conceptualización de cultura de Sarmiento con la formación de una identidad nacional argentina. Aludiremos a Recuerdos de Provincia, Facundo, y Conflicto y armonías de las razas en América. También alumbrarán la discusión los trabajos de Senkman (1989), Garrels (1993), Martínez Echazábal (1988), Viñas (1981), Zea (1989)y Rovarini (1989). Discutiremos la falta de profundidad del pensamiento de Sarmiento al tratar la cuestión étnica dentro de su proyecto utópico para la creación de una identidad argentina.

En el capítulo III, analizamos la vertiente pragmática de su ideario: el pensamiento educativo y su relación con la visión cultural ya discutida. Usaremos distintos textos y artículos de Sarmiento sobre la educación recogidos en Ideas Pedagógicas (reed. 1938) y los Viajes (reed. 1962). Hablaremos de las 
características esenciales del pensamiento educativo de Sarmiento y las contextualizaremos de acuerdo a las ideas de la época. Utilizaremos un artículo Jean-Georges Kirchheimer (1989) sobre "Los maestros franceses en la educación argentina durante la época de Sarmiento" y otro estudio de Lilia Pérez sobre la situación educativa en Salta antes y después de la intervención política de Sarmiento. 


\section{Capítulo II}

\section{La utopía cultural sarmientina: civilización y barbarie}

"The proof that the state is a creation of nature and prior to the individual is that the individual, when isolated is not self-sufficing and therefore he is like a part in relation to the whole. But he who is unable to live in society, or who has no need because he is sufficient for himself, must be either a beast or a god: he is not part of the state"

Aristoteles from $\underline{\text { Politics }}$

2. 1. La génesis y evolución de un discurso: civilización versus barbarie.

El discurso sobre la cultura civilizada y la barbarie no es desde luego una idea original de Sarmiento, ni del romanticismo latinoamericano, sino que remite a una larga tradición en el pensamiento occidental. Aristóteles diferenciaba entre los pertenecientes a la polis -la ciudad y núcleo de organización social griega-, en especial a la gran Atenas, y los pueblos bárbaros. Esto es, los pertenecientes al Estado y los sin-Estado, dioses o bestias según la definición del ilustre griego.

Quizá es aquella también la época y el lugar en que se empieza a manejar la idea de progreso, ligada sin duda a la concepción del tiempo, en la física de Aristóteles, como algo objetivo y linear, definido por la dimensión de espacio. En efecto hay que recordar que para Aristóteles el tiempo es un número referido al 
movimiento y que se puede contabilizar por la comparación con un antes y un después ${ }^{2}$.

De este modo, y según esta conceptualización objetiva, el tiempo (y por ende la historia) no es algo cíclico sino que sigue una progresión espaciolineal ascendente: el pasado, el ahora, lo que vendrá... ${ }^{3}$

En el siglo XIX en Europa y América Latina, veremos que Sarmiento no es tampoco pionero en su época a la hora de rescatar la noción de progreso. Para empezar, en el racionalismo francés de los siglos XVII, XVIII, en el pensamiento ilustrado, subyace esta perspectiva objetiva y linear del tiempo. En efecto para estos intelectuales y científicos (Descartes, Condorcet, Compte...) el tiempo es un proceso linear progresivo, irreversible, continuo y que puede ser comprendido científicamente ${ }^{4}$. En 1793 el marqués de Condorcet escribe "Bosquejo de un cuadro histórico de los progresos del espíritu humano", donde elabora su teoría del progreso. Para Condorcet el ser humano estaba entonces comenzando una nueva era en la que los vicios y las desigualdades llegarían a desaparecer. Aunque hoy nos parezca ingenuo, tanto él como sus coetáneos tenían fé en que la razón por sí sola podría traer la felicidad y la igualdad, creían en definitiva que el simple

\footnotetext{
${ }^{2}$ Basado en mi investigación y estudios para la clase de « Time and Human condition » impartida por el Dr. Charles Schmidtke en Canisius College, Buffalo, verano de 1998, como parte del programa de estudios conducente a un certificado de post-grado en Gerontología.

3 Podemos extraer tres características fundamentales de la definición aristotélica. 1) La primera, ya mencionada, es que el tiempo es algo objetivo. Es decir, el tiempo existe independientemente del hombre. El tiempo pasa haya o no haya un ser vivo involucrado y consciente de este proceso. Y ocurre en un continente o recipiente que es el mundo. 2)Como consecuencia de lo anterior, el tiempo es divisible. 3) Por último, es simultáneo, o sea, ocurre en todas partes a la misma vez.

${ }^{4}$ Ya en nuestro siglo el escritor y filósofo $\mathrm{H}$. Bergson desafía este concepto y ofrece otra formulación. Existe un tiempo objetivo fabricado por nuestro intelecto, pero epistemológicamente hablando, existen dos formas de comprender la realidad, una a través de estrategias o instrumentos intelectuales como la razón y la lógica, y la otra por medio de la intuición, ya que la vía intelectual no consigue capturar el flujo y la dinámica de la realidad (léase también, del tiempo).
} 
reconocimiento de los derechos naturales del hombre bastaría para alcanzar la anhelada utopía 5 .

El concepto de progreso y la metáfora cultural de la civilización y la barbarie que lo representa tiene, como vemos, una larga y fructífera historia. Ya en el siglo XX, el filósofo alemán Walter Benjamín -sin abandonar la fórmula- le quiso dar la vuelta a la incuestionada civilización, a través de la recuperación de la historia que no aparece consignada en los libros:

«Cultural history represents its contents by means of contrasts (...) The products of art and science owe their existence not merely to the effort of the great geniuses that created them, but also to the unnamed drudgery of their contemporaries. There is no document of culture which is not at the same time a document of barbarism. No cultural history has yet done justice to this fundamental state of affairs, and it can hardly hope to do so" 6

En la teoría crítica contemporánea, gracias al trabajo de "deconstrucción" de Derrida se ha llegado a profundizar en el estudio de los mecanismos y limitaciones de la lógica y metafísica occidental a la hora de representar en un texto la explicación de un fenómeno. Según Derrida esta forma discursiva a menudo presenta una realidad bipolar y jerárquica, donde el primer término define una serie de valores y define al segundo término con otros valores opuestos y

\footnotetext{
5 "Este progreso está sometido a las mismas leyes generales que se observan en el desenvolvimiento de nuestras facultades, puesto que es el resultado de este desenvolvimiento (...) [Condorcet se propone mostrar] ...que la perfectibilidad del hombre es indefinida ; que los progresos de esta perfectibilidad, independientes de todo poder que quisiera detenerlos (...) Sin duda que estos progresos podrán seguir una marcha más o menos rápida, pero jamás será retrógada » Marqués de Condorcet « Teoría del progreso » en « Filosofía de la historia » recopilado por Cardiel Reyes, R. (1980) : Los filósofos modernos en la independencia latinoamericana. Universidad Nacional Autónoma de México, México, pp. 294-295.
} 
subordinados a los primeros. Es interesante para el objeto de nuestra tesis el análisis crítico de Derrida, puesto que Sarmiento utiliza también una fórmula bipolar, la manida antinomia "civilización y barbarie" para presentar en sus obras lo que hemos llamado su conceptualización de la cultura. Así explica J. Derrida el funcionamiento de este recurso discursivo:

«1. The hierarchical axiology, the ethical-ontological distinctions which do not merely set up value oppositions clustered around an ideal and undefinable limit, but moreover subordinate these values to each other : normal/ abnormal, standard/ parasite, fulfilled/ void, serious/ non-serious, literal/ non-literal, briefly : positive/ negative and ideal/ non-ideal.

2. The enterprise of returning strategically, ideally, to an origin held to be simple, intact, normal, pure, standard, self-identical, in order then to think in terms of derivation, complication, deterioration, accident, etc., ... conceiving good before evil, the positive before the negative, the pure before the impure... the essential before the accidental, etc."

"La civilización y la barbarie" formaba parte del bagaje intelectual de los pensadores americanos. El suizo Rousseau, tan admirado por Sarmiento y por muchos de sus coetáneos en América, había creado el mito del «buen salvaje » que tan bien se ceñía al discurso de la justificación política de los liberales ${ }^{7}$ y que, como veremos más adelante se encuentra a la base de la tesis sarmentina.

\footnotetext{
${ }^{6}$ Walter Benjamin de Philosophy of History en Adams y Searle (ed.) Critical Theory since 1965. Florida State University Press. Tallahassee

${ }^{7}$ Recordemos aquí que según Jean Jacques Rousseau el desarrollo político del hombre atraviesa tres etapas. La primera es el estado de la naturaleza, en el cual el hombre vive disperso y tiene sólo
} 
Félix Weinberg en su estudio « La dicotomía civilización-barbarie en nuestros primeros románticos », señala que la antinomia «civilización versus barbarie » como conceptualizaciones culturales más o menos restringidas, empieza a ser popular en el Río de la Plata desde principios del XIX. « Aparecen el Telégrafo Mercantil, en el Semanario de Agricultura, Industria y Comercio y en el Correo de Comercio (...) En el mensajero argentino de 1827, periódico de tendencia rivadiana, hallamos por vez primera la dicotomía de civilizaciónbarbarie. En Otro periódico (1831), de los exiliados unitarios en Montevideo, se reitera la antinomia. En los escritos de los románticos también se puede verificar la circulación de esas palabras de origen iluminista $»^{8}$ (p. 8 ) « Hay una concepción ideológica común, sustentada a partir de la elaboración local del romanticismo social, de decisiva gravitación en los ámbitos intelectuales rioplatenses durante la cuarta y quinta década del siglo pasado ${ }^{9}$ (p. 10)

Weinberg considera que Echeverría- el iniciador del romanticismo social en América- es el primero en enunciar la tesis de que en las revoluciones aparecen siempre dos ideas enfrentadas « la idea estacionaria, que quiere el statu quo, y se atiene a las tradiciones del pasado, y la idea reformadora y progresiva; el régimen antiguo y el espíritu moderno »

una relación esporádica y poco frecuente con otros hombres. La segunda etapa es un período de desigualdad política, debida a la creación de la propiedad privada y en la que los gobiernos establecen diferencias entre débiles y poderosos, amos y esclavos. Por último, el « contrato social » eleva nuevamente al hombre a una etapa de libertad y felicidad, que destruirá la desigualdad creada en la etapa anterior.

${ }^{8}$ Félix Weinberg "La dicotomía civilización y barbarie en nuestros primeros románticos " Río de La Plata: Culturas, 1989, vol. 3, no 13, p. 5-18.

${ }^{9}$ Op. cit. 
En definitiva, en torno al debate recurrente sobre la civilización y el progreso podemos concluir que la proeza de Sarmiento consistió no en la originalidad de la fórmula, sino en que logró definir y retratar como nadie antes hubiera hecho, esa supuesta lucha entre dos fuerzas sociales, una diada poética que viene a querer representar la historia argentina y latinoamericana, pero cuyo carácter es en sí universal, como hemos visto ${ }^{10}$. Así se explica Sarmiento:

"Es consolador (...) que sean humanos y no locales las aspiraciones que nos impulsan. Cuando esta ciudad se degollaba, se obedecía a un instinto local argentino de que no participaba pueblo alguno por entonces. Guardémonos de separarnos de la huella que nos dejan trazada los pueblos que nos preceden en la marcha de la civilización"11

Algunos críticos han visto la riqueza y atracción de "lo bárbaro" en la literatura latinoamericana. Especialmente atractiva resulta la barbarie para los escritores del romanticismo social americano. En la literatura de Sarmiento el poder emotivo de la barbarie ejerce una atracción singular, lo representa de forma paradójica en una especie amor-odio, de admiración y crítica. Con este recurso en el Facundo Sarmiento se une a la corriente literaria romántica en Latinoamérica:

\footnotetext{
${ }^{10}$ Como dice Antonio Mitre en su artículo : «...la única historia que interesa en el libro [Facundo] [es] : la constitución de la modernidad americana. Bajo esta perspectiva, las nociones de civilización y barbarie, en vez de aludir a espacios geográficos o históricos definidos, representan más bien los ingredientes elementales que, en proporción variada, constituyen la substancia híbrida de que está hecha toda modernidad (...) En tal sentido el Facundo muestra el caso aleccionador de una realidad que ha perdido la inocencia de la barbarie pero que aún no ha sido domesticada por la civilización » Mitre, A. « La parábola del espejo : identidad y modernidad en el Facundo de Domingo F. Sarmiento » Revista de crítica literaria latinoamericana, Año XX, No 39, Lima, primer semestre de 1994, p. 20)

${ }^{11}$ Sarmiento, D. F. Discursos. Buenos Aires, 7 de noviembre de 1885. Tomo XXII, p. 295
} 
"Si un destello de literatura nacional puede brillar momentáneamente en las nuevas sociedades americanas, es el que resultará de la descripción de las grandiosas escenas naturales, y sobre todo, de la lucha entre la civilización europea y la barbarie indígena, entre la inteligencia y la materia" [El subrayado es mío].

Cuando el sanjuanino comienza su "ensayo-novela" Facundo describiendo y catalogando, a modo de sociólogo o antropólogo cultural, los distintos tipos de gaucho: cantor, baqueador, rastreador... aunque parte de una cultura "bárbara" crea unos personajes de extraordinarias cualidades naturales, con habilidades casi fantásticas a pesar de no haberse beneficiado de la ciencia moderna de la civilización europea.

Por eso también el personaje de Facundo Quiroga -nacido también en la campaña argentina-, con su valorización ambivalente, positiva y negativa a la vez, destila un cierto poder de embrujo. Sarmiento parece fascinado por su temperamento, fortaleza física, valentía, y la capacidad para ejercer el poder sobre otros $^{12}$, si bien condena el egoísmo y el apoyo al gobierno tiránico de Rosas.

En su artículo «La seducción de la barbarie en el Facundo » María Rosa Lojo, remitiéndose al ensayo por Rodolfo Kush La seducción de la barbarie ${ }^{13}$, elabora un análisis estilístico del Facundo al estudiar, precisamente, « lo bárbaro » como recurso poético. Según la autora, para Kush la barbarie corresponde a lo que

\footnotetext{
${ }^{12}$ Como dicen Barrenechea y Lavandera (1967): "La figura de Facundo revela, por su fuerza y espontaneidad, la naturaleza americana que necesitaba presentar para apoyar su tesis del medio, y su energía natural, aunque bárbara, producía, sin duda, la resonancia afectiva que Sarmiento buscaba" en Domingo Faustino Sarmiento. Enciclopedia Literaria. Buenos Aires, Argentina, p. 29 ${ }^{13}$ Publicado en Buenos Aires, Raigal, 1953.
} 
no es europeo, lo irracional, lo vital, natural, oscuro y ejerce una especie de hechizo incluso sobre sus más acerbos críticos.

Para María Rosa Lojo, Sarmiento construye el Facundo como prototipo estético de la barbarie a partir de una serie de procedimientos: 1) La mitificación literaria: extra-humanidad (extra-occidental) de Facundo, e inscripción del personaje en diversos sistemas: lo ultramundano, lo animal, lo monstruoso, el oriente; 2) La heroización positiva: relaciones con la virtus occidental y la sublimidad clásica; 3) La representatividad antropológica: Facundo y la esencia de lo americano y de lo humano originario ${ }^{14}$. Además, se puede leer el Facundo a la luz de la teoría de la arquitectura metafísica de « deseo según el otro » expuesta por René Girard en su ensayo Mentira romántica y verdad novelesca. Según María Rosa Lojo la relación narrativa Sarmiento-Facundo, convierte al personaje en una suerte de alter ego encandilante y abominable. Al mismo tiempo existe también -según esta autora- una atracción en relación al antihéroe, Rosas, ya que Sarmiento quisiera de algún modo estar en el lugar de Rosas.

Civilización y barbarie serán finalmente la forma y materia de que -para Sarmiento- está constituida la modernidad americana.

\footnotetext{
${ }^{14}$ María Rosa Lojo "La seducción estética de la barbarie » Estudios Filológicos, 1992, Vol. 27, pp. 141-148.
} 


\section{2. La "civilización" como utopía en Sarmiento.}

Hemos visto pues la génesis conceptual del esquema sarmentino (civilización versus barbarie). Nos interesa ahora llegar al corazón de su visión política. Fredric Jameson ${ }^{15}$ sostiene que toda literatura no importa en qué grado, debe ser leída como meditación simbólica sobre el destino de una comunidad y que todo texto está por lo mismo imbuido de un impulso utópico. Una lectura tal del texto es especialmente fecunda en el caso de Sarmiento.

A María E. S. de Cywiner (1989) por su artículo « La civilización como utopía en la mira sarmentina » se le debe reconocer la buena intuición de identificar el impulso utópico patente y latente a lo largo del texto. Sin embargo tenemos que discrepar con el análisis por ella elaborado. Para empezar, disentimos con la teoría que la autora utiliza como base de su planteamiento: «...el pensamiento utópico es en esencia: un referirse siempre al futuro, mediato o inmediato, y un futuro opuesto a la realidad actual » (p.87). En nuestra opinión esta premisa es errónea. Hay utopías en efecto que se refieren al futuro, pero también utopías que colocan el paraíso en un tiempo perdido (por ejemplo, en el génesis de la Biblia) o incluso utopías atemporales. La utopía en su significado original- del griego u-topos- quiere decir simplemente un lugar que no existe, osi se toma la etimología eu-topos- un lugar de felicidad, aunque sabemos que también utopías apocalípticas -la bien conocida de G. Orwell por ejemplo.

\footnotetext{
${ }^{15}$ Jameson, Fredric (1981): The political unconscious. Narrative as a socially symbolic act. Cornell University Press. Ithaca. New York.
} 
Cywiner (1989) también cree que ciertos escritos de Sarmiento merecen el calificativo de utópicos, según ella porque reflejan la visión y previsión agorera de un tiempo por venir. En nuestra opinión, existen obviamente elementos utópicos, en términos de la formulación explícita de una ideología, pero Sarmiento no escribió una utopía, escribió sobre un lugar y tiempo y personajes concretos y lo hizo para dar su interpretación acerca de las fuerzas históricas y sociales operantes en ese contexto. Lo que sí es válido, desde nuestra perspectiva, es adoptar el término « utopía » para designar el conjunto trabado de ideas que constituyen el transfondo político e ideológico de la literatura sarmentina. Así entendida coincidimos una vez más con María Cywiner en que la «Civilización » resume la definición de esta utopía.

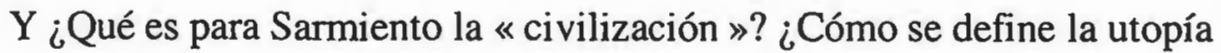
sarmentina?. En sus propias palabras:

«La civilización de un pueblo sólo pueden caracterizarla la más extensa apropiación de todos los productos de la tierra, el uso de todos los poderes inteligentes y de todas las fuerzas materiales, a la comodidad, placer y elevación moral del mayor número de individuos $»^{16}$

Podemos notar qué criterio utiliza Sarmiento para definir lo que entiende él por cultura civilizada. Y ese criterio es: la eficiencia económica en la utilización de los medios de subsistencia, teniendo como principio filosófico una base utilitarista, es decir, proporcionar el mayor placer al mayor número de

\footnotetext{
${ }^{16}$ Sarmiento, D. F. (1961) : Viajes. Europa-Africa-América. Selección. Editorial universitaria de Buenos Aires. Argentina, p. 97.
} 
personas. Esta línea de pensamiento utilitarista es la que el Sarmiento político aplica, por ejemplo a la educación.

La ideología de Sarmiento, como la de muchos otros intelectuales latinoamericanos en su época, está muy influida por el pensamiento ilustrado. Sin duda Sarmiento refleja en su ideario la influencia de los escritores y pensadores de la Europa iluminista. Más en concreto aquí Sarmiento manifiesta su afición al pensamiento utilitarista de Diderot o del inglés Hume. Según esta filosofía desde un punto de vista materialista existe solamente un criterio o premisa en que basar una moral, y este es el criterio de la utilidad de las acciones humanas. El individuo opera según el cálculo de las conveniencias que sus acciones le retribuyen según las consecuencias sean placenteras o dolorosas. En esta misma línea de pensamiento, el Estado deberá de obrar también de forma que los resultados de las acciones produzcan el mayor bienestar al mayor número de personas.

De esta manera atendiendo a los criterios arriba mencionados, es como Sarmiento descubre que los Estados Unidos son en su tiempo el pueblo más civilizado del mundo.

"Los europeos se burlan de estos hábitos de rudeza, más aparente que real, y los yanquis, por espíritu de contradicción, se obstinan en ellos, y pretenden ponerlos bajo la égida de la libertad y del espíritu americano. Sin favorecer estos hábitos, ni empeñarme en disculparlos, después de haber recorrido las primeras naciones del mundo cristiano estoy convencido de que los norteamericanos son el único 
pueblo culto que existe en la tierra, el último resultado obtenido de la civilización moderna"17 [El subrayado es mío]

Sarmiento menciona la ética del trabajo, la superioridad viril como cualidades a emular de los vecinos de Norteamérica, últimos en la historia de las grandes civilizaciones:

«Los norteamericanos sólo pueden ser comparados hoy a los romanos antiguos, sin otra diferencia que los primeros conquistan sobre la naturaleza ruda por el trabajo propio, mientras que los otros se apoderan por la guerra del fruto creado por el trabajo ajeno. La misma superioridad viril, la misma pertinacia, la misma estrategia, la misma preocupación de un porvenir de poder y grandeza $»^{18}$

Pero como ya se ha apuntado también Sarmiento siente además una profunda admiración por el pensamiento y la cultura franceses. Si la civilización de un pueblo tiene como definición político-pragmática la que vimos y como modelo el norteamericano, la cultura como refinamiento de las costumbres en el plano más personal tiene un paradigma europeo, concretamente el del pueblo galo:

"El francés de hoy es el guerrero más audaz, el poeta más ardiente, el sabio más profundo, el elegante más frívolo, el ciudadano más celoso, el joven más dado a los placeres, el artista más delicado, y el hombre blando en su trato con los otros. Sus ideas y sus modas, sus hombres y sus novelas, son el modelo y la pauta de todas las otras naciones; y empiezo a creer que esto que nos seduce

\footnotetext{
${ }^{17}$ Op. cit., p. 110

${ }^{18}$ Ibíd., p. 111
} 
las lecturas desordenadas de veinte años habían podido dejar, buscando la aplicación de aquellos resultados adquiridos a la vida actual, traduciendo el espíritu europeo al espíritu americano, con los cambios que el diverso teatro requería" ${ }^{21}$ [El subrayado es mío]

José Martí en Nuestra América ataca precisamente esta tesis Sarmentina: la necesidad de emulación de los pueblos o razas "superiores". Muy al contrario para Martí no hay que buscar la justificación de la situación de América Latina sobre la base de un prejuicio racial. Sólo existe una raza, nos dice, la raza humana. También Henríquez Ureña acusa a Sarmiento de querer buscar atajos para la solución a los problemas de América Latina. No se trata de copiar modelos, dice Martí por su parte, sino de aplicar los conocimientos más avanzados a la realidad de América Latina, que es una realidad nueva por su naturaleza misma ${ }^{22}$

El centro y vértice por antonomasia de la civilización, el origen del progreso de las sociedades, es la ciudad ${ }^{23}$. Por el contrario para Sarmiento la soledad de la pampa, la vida nómada y pastoril, dificultan cualquier tipo de organización política y de progreso:

\footnotetext{
${ }^{20}$ Op. cit., p. 62.

${ }^{21}$ Sarmiento, D. F. reed. (1962): Recuerdos de Provincia. Sur. Buenos Aires, p. 184.

22 «... el buen gobernante en América no es el que sabe cómo se gobierna el alemán o el francés, sino el que sabe con qué elementos está hecho su país, y cómo puede ir guiándolos en junto, para llegar, por métodos e instituciones nacidas del país mismo, a aquel estado apetecible (...) La forma de gobierno debe avenirse a las constitución del país (...) No hay batalla entre la civilización y la barbarie, sino entre la falsa erudición y la naturaleza. El hombre natural es bueno y acata y premia la inteligencia superior, mientras ésta no se vale de su sumisión para dañarle, o le ofende precindiendo de él ... » « El vino de plátano ; y si sale agrio, es nuestro vino ! (José Martí de Nuestra América)

23 "La ciudad es el centro de la civilización argentina, española, europea; allí están los talleres de las artes, las tiendas del comercio, las escuelas y colegios, los juzgados, todo lo que caracteriza, en fin, a los pueblos cultos" de Sarmiento, D. F. reed. (1940): Facundo. Ediciones Estrada, Buenos Aires, Argentina, p. 43.
} 
"No puede haber progreso sin la posesión permanente del suelo, sin la ciudad, que es la que desenvuelve la capacidad industrial del hombre y le permite extender sus adquisiciones"24

Para Sarmiento la campaña no es sólo inadecuada para el progreso económico, intelectual del hombre sino además para su progreso moral. El hombre de la pampa vive en una libertad sin más leyes que las de su propia fuerza, esto queda ejemplificado en su descripción del gaucho malo. A esta tesis se opone la de José Hernández en Martín Fierro quien en la creación del personaje del gaucho le da la oportunidad a este de defenderse de esta acusación : «Y sepan cuantos escuchan/ de mis penas el relato,/ que nunca peleo ni mato/ sino por necesidá,/ y que tanta alversidá/ sólo me arrojó el mal rato./ Y atiendan la relación/ que hace el gaucho perseguido,/ que padre y marido ha sido/ empeñoso y diligente,/ y sin embargo la gente/ lo tiene por un bandido »

${ }^{24}$ Op. cit., p. 46. 


\section{3. Civilización e identidad argentina.}

Sabemos que Sarmiento era amante de las biografías de grandes hombres, ya que a su manera de ver personalizan el resultado de unas determinadas fuerzas históricas y pueden edificar al pueblo con su ejemplo ${ }^{25}$. En Recuerdos de Provincia Sarmiento se pone a sí mismo como ejemplo de la capacidad de transformación del hombre humilde americano a través de la cultura. Como dice Anderson Imbert ${ }^{26}$, Sarmiento sentía su propia vida como "un drama histórico que se estaba representando dentro de la civilización". Y no sólo se pone a sí mismo como ejemplo vivo de transformación, en Recuerdos... propone además el modelo del futuro hombre americano o argentino: una suerte de híbrido que reúne la fuerza y bravura de la barbarie americana elevada por la cultura europea a un nivel de sofisticación óptimo. Su tío y mentor Don Domingo Oro ofrece el modelo de este tipo argentino:

"Oro ha dado el modelo y el tipo del futuro argentino, europeo hasta los últimos refinamientos de las bellas artes, americano hasta cabalgar el potro indómito: parisiense por el espíritu, pampa por la energía y los poderes físicos"27

Como es sabido una de las claves para alcanzar este ideal se tradujo en la política de inmigración proveniente de Europa que el Sarmiento en su faceta política defiende y lleva a término. Esta inmigración debería de tener -según el sanjuanino- una influencia transformadora del carácter nacional para llegar a

\footnotetext{
${ }^{25}$ Extenderemos esta idea en el capítulo siguiente.

${ }^{26}$ Anderson Imbert, E. (1967): Genio y figura de Samiento. Eudeba editorial universitria de Buenos Aires, Argentina.

${ }^{27}$ Sarmiento, D. F. (1962) : Recuerdos de Provincia. Ed. Sur. Buenos Aires, p. 101.
} 
construir la "utopía" cultural argentina. Sin embargo Leonardo Senkman (1989)

en un interesante estudio de esta pragmática sostiene que uno de los errores

fundamentales de la política de Sarmiento fue la falta de reflexión sobre la cuestión étnica ${ }^{28}$.

Sarmiento ve como más positiva la identificación de Estado y nación y la homogeinización de la cultura ${ }^{29}$. Como sabemos hay en su opinión una forma mejor y óptima de cultura y civilidad hacia la que todos los pueblos modernos tienden.

Sin embargo la falta de profundización en estas cuestiones le impidió a Sarmiento prever una de las flaquezas de su política. Los nuevos inmigrantes, especialmente italianos, no se sintieron automáticamente argentinos ni inclinados a defender los intereses de la patria. Sarmiento criticó su desarraigo, la ausencia de patriotismo, el egoísmo particularista, la deslealtad al país etc. (Senkman, 1989, p. 55)

Algunos críticos además han calificado a Sarmiento como racista (Martínez Echazábal, L.1988 ; Garrels, E., 1993 ; Viñas, 1981). Sin duda sus juicios son muchas veces estereotípicos y cargados de prejuicios raciales. En nuestra opinión, Sarmiento asimila en muchas ocasiones los términos de raza y

${ }^{28}$ Senkman, L. "Sarmiento y la cuestión étnica » Río de la Plata : Culturas. Paris. Vol. 8, 1989, pp. $45-59$

29 Ciertamente, es significativo observar que en sus viajes Sarmiento estudia las diferentes formas de gobierno, la industria, la educación y sin embargo no se plantea el problema de la convivencia de diferentes etnias en un mismo territorio nacional. Es más, en su visita a España, por ejemplo, Sarmiento advierte las diferencias linguísticas y culturales de los distintos territorios que forman el Estado, pero -identificando nación con Estado- opina que tales diferencias son óbice para la cohesión del territorio, es decir, son un signo de primitivismo y no de modernidad: "Esta diversidad de trajes, muy pintoresca, sin duda revela, sin embargo, una de las llagas más profundas de la España: la falta de fusión en el Estado. Las provincias españolas son pequeñas naciones diferentes y no partes integrantes de un solo Estado" ${ }^{29}$ (Viajes, 1962, p. 71) 
cultura. Asimismo para él hay ciertas razas que no tendrían la habilidad política de la raza blanca ${ }^{30}$. Así se explica por ejemplo en Confictos y armonías de las razas en América:

"El norteamericano es, pues, el anglosajón exento de toda mezcla con razas inferiores en energía, conservadas intactas sus tradiciones políticas, sin que se degraden con la adopción de las ineptitudes de raza para el gobierno, que son orgánicas del hombre prehistórico" (citado por Zea, 1989, pp. 89-90)

También en Facundo habla de la ociosidad de ciertas razas, incluida la española $^{31}$, pero al mismo tiempo una de las razones para esta ociosidad -además de la raza- es el entorno geográfico mismo, la pampa como escenario de la barbarie, que hace brotar en el hombre sus instintos más primitivos:

"Las razas americanas viven en la ociosidad, y se muestran incapaces aún por medio de la compulsión, para dedicarse a un trabajo duro y seguido. Esto sugirió la idea de introducción de negros en América, que tan fatales resultados ha producido. Pero no se ha mostrado mejor dotada de acción la raza española, cuando se ha visto en los desiertos americanos abandonada a sus propios instintos"32

Otra de las cosas que Sarmiento destaca en Conflictos y armonías... es el mestizaje como una de las diferencias más notorias entre la colonización de la

\footnotetext{
${ }^{30}$ Para un estudio en profundidad sobre este tema véase también el estudio de Zea, Leopoldo « El proyecto de Sarmiento y su vigencia » Cuadernos americanos, 1989, Vol. 3, pp. 85-96.

${ }^{31}$ Véase Rovarini, Maria R. "Algunas reflexiones de Sarmiento sobre la colonización española en América: conflicto y armonía de las razas en América 1883-1888" Río de la Plata: Culturas. Vol. 9, 1989, pp. 25-32: La autora analiza la ambivalencia del significado de España en el ideario de Sarmiento: España es ora portadora de la civilización, ora causante del subdesarrollo. Según la Rovarini es la España Medieval, con sus instituciones y el sistema de colonización que lleva a América, la España a la que Sarmiento atribuye uno de los factores de retraso de América Latina. ${ }^{32}$ Sarmiento, D. F. reed. (1940): Facundo. Ediciones Estrada, Buenos Aires, Argentina, p. 39.
} 
América anglosajona y la española, mestizaje que según Rovarini (1989) viene a insertarse de nuevo en el corazón de la dualidad "civilización y barbarie".

Sin embargo en otras ocasiones Sarmiento manifiesta su admiración hacia el "mulato" en quien él ve el producto también de un mestizaje beneficioso. Sarmiento es seguramente partícipe de la ideología del blanqueamiento ${ }^{33}$. Muchos de los prejuicios y estereotipos que Sarmiento pronuncia en repetidas ocasiones estaban apoyadas, en su época, por alguna de las teorías científicas y filosóficas en boga: la frenología, la teoría de los climas, el positivismo spenceriano, etc. que hoy día son rechazadas por inválidas ${ }^{34}$. Así se refiere al mulato en los Viajes:

"El mulato se levanta en el Brasil amenazando vengar bien pronto las injurias hechas a su tostada madre. Raza viril que conserva la sangre ardiente del africano, templada para bullir bajo los rayos verticales del sol, al mismo tiempo que la organización de su cráneo lo liga a la familia europea. Dumas, Heredia, Pétion, Barcala, aquellos hombres notables brillan por las artes, la música, la poesía y las ciencias médicas"

Sus juicios, en efecto, dan también un retrato negativo de determinado grupo étnico o racial: el negro, el indígena,... Estas opiniones se basan fundamentalmente en la comparación con unas ciertas formas culturales y formas de organización política de otros grupos sobre todo de la Eropa del Norte y Norteamérica a quienes Sarmiento considera superiores en estos aspectos civiles y políticos. A pesar de la "inferioridad" de la raza que existe según Sarmiento

\footnotetext{
${ }^{33}$ Véase para profundizar en esta idea un estudio de Jackson, Richard L. (1976) : Black Image in Latin American Literature. Alburquerque : University of New Mexico Press.

${ }^{34}$ Para un estudio en profundidad de esta cuestión véase alguno de los estudios citados : Martínez Echazábal, 1988 ; Garrels, 1993 ; Viñas, 1981.
} 
pretende de alguna forma « redimir », según su visión, a los grupos o razas "inferiores" para elevarlos y elevar al continente a formas de vida más "modernas" y "civilizadas":

"Me detengo sin quererlo sobre las brillantes cualidades morales de esta raza intermediaria entre el blanco que se enerva en los climas ecuatoriales y el negro incapaz de elevarse alas altas regiones de la civilización. Otra vez había notado la predisposición constante del mulato a ennoblecerse, y su sentimiento exquisito del arte, que lo hace instintivamente músico. Viénele la primera cualidad de haber ensanchado su frente, y la segunda de la sangre africana que calienta su nuevo y más idóneo cerebro"35 [el subrayado es mío]

Parece que el Sarmiento maduro comienza a darse cuenta de que su política "civilizadora" el intento de realización de su utopía no ha dado los frutos esperados, la cuestión de la identidad está aún por resolverse:

«¿Qué es la América? ¿Es acaso la vez primera que vamos a preguntarnos quiénes éramos cuando nos llamaron americanos y quiénes somos cuando argentinos nos llamamos?

¿Somos europeos? - Tantas caras cobrizas nos desmienten.

¿Somos indígenas? - Sonrisas de desdén de nuestras blondas damas nos dan acaso la única respuesta.

¿Mixtos? - Nadie quiere serlo, y hay millares que ni americanos ni argentinos querrían ser llamados.

${ }^{35}$ Sarmiento, D. F. (1961) : Viajes. Europa-Africa-América. Selección. Editorial universitaria de Buenos Aires. Argentina, p. 34. 
¿Somos nación? ¿Nación sin amalgama de materiales acumulados, sin ajuste ni cimiento?

¿Argentinos? - Hasta dónde y desde cuándo, bueno es darse cuenta de ello $»^{36}$ [el subrayado es mío].

${ }^{36}$ Prolegómenos, "Conflictos y armonías de las razas en América » Obras completas, p. 27. Citado por Senkman (1989). 


\section{Capitulo III}

\section{La educación como instrumento civilizador}

"A la educación de los americanos he consagrado toda mi existencia, no en la parte que hace a la ciencia, que yo no poseo, sino en la difusión de los sencillos medios de adquirirla"

--Las Razas. Yungai, octubre II de 1853. Tomo XVI. Pag. 91--

La educación fue para Sarmiento un objetivo y constante lucha a lo largo de su vida en lo personal, profesional y la política. Por esta razón no sería posible hacer una lectura comprensiva de su obra obviando una parte tan esencial del carácter de Faustino Sarmiento. Ignorar la por el mismo reconocida pasión y obsesión por proporcionar los medios adecuados para la instrucción - una tarea que motivó a Sarmiento en lo público, pero también en el esfuerzo por su propia formación personal- sería equivalente a no reconocer lo que recordando a Miguel de Unamuno podríamos calificar como la misión en la vida de Domingo Faustino Sarmiento. Este esfuerzo por mejorar las condiciones de la educación del pueblo argentino, en la dotación de recursos, la innovación pedagógica, la creación de escuelas y bibliotecas de los pueblos debe ser reconocido.

Se han escrito algunos estudios que tienen por objeto analizar precisamente alguna de las contribuciones del argentino en la conformación de un 
sistema educativo, pero estos análisis se centran más en algún aspecto

administrativo o pedagógico. Nosotras no vamos adoptar esta perspectiva, nos

interesa más bien analizar su obra a la luz de esta vocación por educar a una

audiencia de acuerdo con unos determinados parámetros culturales. Sarmiento lo hace con vehemencia a veces, sumergido en un mar de estilos y géneros literarios variados y difusos para presentar ejemplos, historias, modelos a través de una literatura teñida de idealismo y de fondo quijotesco, puesto que busca transformar la sociedad argentina de su tiempo, por la fuerza de la "cultura civilizada", a través de la educación.

Sin duda la preocupación de Sarmiento por la instrucción pública debemos encajarla dentro del contexto histórico-social del siglo XIX, el siglo en que se promulgan, primero en Francia y luego en el resto de Europa y América, las primeras leyes de la enseñanza primaria universal, laica, pública y obligatoria. Es la época en que se ve la necesidad de escolarizar a las masas, consecuencia ineludible del desarrollo industrial y la modernización de las sociedades. Aparece por primera vez en diversos países una cartera o ministerio de educación. Los gobiernos invierten una importante proporción de su capital en la creación de escuelas. Se experimenta con nuevas metodologías de enseñanza, nuevas teorías de la educación... y Sarmiento es un acólito más del lema "progreso y educación" 37 .

\footnotetext{
34. Basado en mis estudios e investigación sobre la Historia de la escolarización para la obtención de una Licenciatura en Pedagogía en la Universidad de Oviedo, España. Para más información véase también Green, Andy (1954) Education and State Formation: the rise of education systems in England, France and the USA. New York: St. Martin's Press, reed. 1990.
} 
"Ahora, nosotros para hacer una cosa digna de nuestra posición en nuestra época, tenemos que fundar la República, el gobierno futuro, y eso se funda exclusivamente en las escuelas, por más que esta palabra suene humildemente a nuestros oídos. La escuela es la organización definitiva encontrada por las sociedades modernas para los intereses morales, materiales, industriales y políticos. De la escuela parten y a ella vuelven todos sus resortes" 38 Movidos por esta sed de encontrar unas bases sólidas sobre las que fundar los sistemas educativos nacionales, los gobiernos envían a Ministros y expertos en educación sobre todo a Europa, pero también a Norteamérica y otros países. También Sarmiento viaja por Europa, Africa y Norteamérica para estudiar los sistemas educativos, y de estas observaciones y experiencias nacen sus Viajes. Sarmiento escribe los Viajes en forma epistolar con modestia por su incursión en un género que como él reconoce al principio del libro no domina. Recoge sus impresiones de viaje guiado por el deseo impaciente del ministro viajero que aprende formas nuevas de organizar y estructurar la educación, pero también del hombre que observa fascinado las costumbres, el folklore y carácter, la cultura en definitiva de los pueblos que recorre.

Como pedagogo Sarmiento escribió también libros de texto para la enseñanza así como artículos o discursos sobre su pensamiento educativo, de los que vamos a hacer uso también para acercar al lector esta vertiente de su pensamiento. Pero sin duda la más llamativa desde el punto de vista literario es la narración de su propia formación. La autobiografía de Sarmiento Recuerdos de

${ }^{38}$ Edificios y fondos de escuelas. Senado, Buenos Aires, sesión del 5 de agosto de 1858 . Tomo XVIII, p.17 
Provincia. Porque para Sarmiento una de las lecturas más edificantes para la educación popular son las biografías de los grandes hombres, que sirven como modelo moral de voluntad y patriotismo, como la vida de Franklin a quien admira profundamente y que también escribe. Y aún más interesante para el objeto de nuestra tesis, al crear el personaje de su propia persona en Recuerdos de Provincia se coloca a sí mismo como ejemplo de transformación de lo que puede ser la transformación de la sociedad americana. Del talento rudo sin pulir a la vida civilizada, por medio de un camino de voluntarismo y educación constante ${ }^{39}$.

El análisis que hacemos aquí servirá al lector para apreciar con más detalle el cuadro de la obra de Sarmiento. Veremos las implicaciones de la conceptualización de la cultura que Sarmiento manifiesta con su pensamiento y políticas educativas. Antes de nada recordemos como definía Sarmiento en sus viajes la civilización de un pueblo:

"La civilización de un pueblo solo pueden caracterizarla la más extensa apropiación de todos los productos de la tierra, el uso de todos los poderes inteligentes y de todas las fuerzas materiales, a la comodidad, placer y elevación moral del mayor número de individuos" 40

Hemos visto en el capítulo anterior que Sarmiento quiere emular a los pueblos más civilizados de su época, a su entender: Estados Unidos y Francia. De ahí consecuentemente vendrán los dos modelos principales a la hora de inspirar un sistema educativo argentino.

39 "La biografía es, pues, el compendio de los hechos históricos más al alcance del pueblo y de una instrucción más directa y clara. Mucho trabajo cuesta comprender el enlace de la multitud de acontecimientos que se desenvuelven a un mismo tiempo; pero nada es más fácil, ni hay cosa que 
En líneas generales podemos extraer cuatro características esenciales del pensamiento educativo sarmentino que a continuación pasaremos a enunciar y discutir:

1. La primera, en efecto, es la necesidad de emulación de los pueblos cuya cultura y civilidad aparece como superior.

2. Otra característica es la introducción de las ciencias positivas en el currículo escolar.

3. La naturaleza esencialmente moral de la educación, es decir, la educación de los hábitos de vida.

4. La capacidad de "redención" de las personas en culturas inferiores: el gaucho, el indio, el negro o el mestizo, el hombre de pueblo, a través de la educación.

Para Sarmiento como sabemos los Estados Unidos y Francia son los modelos a imitar. En los Viajes... Sarmiento demuestra su fascinación por estas dos naciones. Si el pensamiento ilustrado sirve como inspiración y justificación intelectual de la revolución americana, la revolución francesa y la independencia americana, respectivamente vienen a materializar en la mira sarmentina el proyecto iluminista. De especial importancia en su pensamiento político y educativo son los franceses o francófonos como Rousseau -especialmente el Emilio o de la educación-, Montesquieu, Tocqueville, Guizot, Thiers, el pedagogo Cousin, por mencionar sólo algunos de los más destacados. 
De los Estados Unidos le inspira sobre todo la realización más fehaciente en la época de los ideales de igualdad, libertad y democracia tan anhelados por políticos y pensadores modernos:

"The United States is something without precedent, a kind of extravaganza which at first shocks and runs counter to one's previous ideas about it, but which is great and noble, occasionally sublime, never disappointing (.) The Republic exists, strong, invencible; her lamp is lit; and someday justice, equality, and law will come to us when the South reflects the light of the North"41

Vayamos por partes. Para comprender el ideario educativo y social de Sarmiento es necesario señalar la influencia que las ideas de Rousseau tienen en el argentino. El Contrato social (1762), y sobre todo el Emilio (1762), donde el suizo teoriza acerca de una nueva perspectiva en educación. En el Contrato social Rousseau dice que el hombre es libre por naturaleza y sin embargo por todas partes se encuentra encadenado. Rousseau está convencido de la bondad humana, pero la sociedad corrupta le ha pervertido. A pesar de que tal aseveración pudiera parecer contraria a la defensa de la necesidad del Estado es todo lo contrario. Para Rousseau, el ser humano vive en un primer momento de su evolución histórica una vida feliz y libre. Es el célebre mito del "buen salvaje" del que hemos hablado ya en el capítulo anterior. Esta libertad que únicamente tiene como necesidad la satisfacción de sus instintos, a la larga devendrá en un segundo estadio evolutivo en que la sociedad organiza instituciones en donde el hombre se encuentra en una situación de desigualdad política. Frente a esta situación el ser humano debe ceder

\footnotetext{
${ }^{41}$ Sarmiento's Travels in the United States. Reed. 1970, p. 116
} 
su libertad al Estado y sólo a través de su contrato social puede ser, paradójicamente, libre.

Del mismo modo que el hombre tiene dentro de sí mismo el germen de bondad que es necesario cultivar

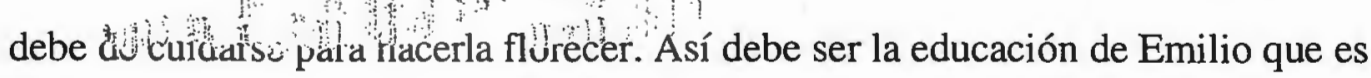
el hombre libre, así ha de ser la formación del ciudadano de la República.

Sin duda Sarmiento se siente atraído por esta idea y menciona en diversas ocasiones, y en muchos de sus escritos a Rousseau, especialmente cuando habla de la educación. Sarmiento recuerda que Rousseau enseña a Emilio a bastarse a sí mismo, por eso le da a leer el Robinson Crussoe ${ }^{42}$. Pero lo que es aún más interesante, para Sarmiento el prototipo norteamericano del "self-made-man" es de hecho una realización de esta idea. Tanto Franklin como el mismo Sarmiento son para él así, hombres hechos a sí mismos por sus méritos y cualidades personales. Esta idea llevada al terreno de la escuela inspirará sistemas educativos que promuevan el ideal meritocrático, es decir, todos los hombres serán tratados sobre una base de igualdad si se asignan los premios correspondientes a sus méritos individuales ${ }^{43}$ :

"Es un rasgo peculiar del espíritu de los americanos el honrar con marcada preferencia a los que llaman self-made-men (hombres formados a sí mismos), contando, gracias a la ilimitada libertad de sus instituciones, con que en todas las épocas de la vida y para toda clase de hombres están abiertos los caminos de

\footnotetext{
${ }^{42}$ Véase Conferencias, Buenos Aires, 1 de enero de 1886. Tomo XXII, p. 315.
} 
engrandecimiento, según su talento y aptitudes; contando, decíamos, con

centenares de estos caracteres animosos, cuyas biografías llenan volúmenes..." 44

A destacar de sus Viajes por los Estados Unidos ${ }^{45}$ son sus impresiones

cuando recorre la ciudad de Boston. Para Sarmiento Boston es cuna de la independencia y democracia Americana, además es la ciudad donde se promulga por primera vez en América la ley sobre la obligatoriedad de la enseñanza primaria. Sarmiento se encuentra sorprendido por la cantidad de escuelas por número de habitantes, por su calidad, así como por la excelencia de sus universidades.

Como presidente de la nación Sarmiento tratará de hacer lo mismo. La difusión de la enseñanza para el progreso de la nación es esencial en Argentina. Al mismo tiempo Sarmiento quiere inspirar la educación en la cultura francesa. En su artículo "Los maestros franceses en la educación argentina durante la época de Sarmiento" (ver bibliografía) Jean-Georges Kirchheimer (1989) nos brinda una prueba valiosa de ello. En su estudio, basado en la investigación y rastreo de archivos históricos, el investigador da los nombres de distintos viajeros franceses llegados al Río de la Plata a partir de la Caída del primer imperio. Sarmiento se sentía atraído por las escuelas de artes y oficios francesas y había usado sus métodos y manuales desde su exilio en Chile. Todos los docentes que llegaron a

\footnotetext{
${ }^{43}$ Este es un tema controvertido aún en nuestros días. La crítica más fuerte del sistema meritocrático en los Estados Unidos surgió en los 70, cuando Jenks hizo su informe sobre el estado de la educación.

${ }^{44}$ Vida de Lincoln. Nueva York, 1866. Tomo XXVII, p. 104.

${ }^{45}$ Sarmiento, D. F. (reed. 1961): Viajes. Europa-Africa-América. Selección. Editorial universitaria de Buenos Aires, Argentina.
} 
ayudarle eran laicos y militantes de las ideas democráticas y republicanas que sufrieron el ostracismo y la persecución por el golpe de estado de Luis Bonaparte.

Además de una renovación de los currículos inspirada en las ciencias positivas modernas y la importancia de las artes manuales y saberes aplicados, Sarmiento también pretende, sobretodo, una regeneración moral del continente. En "Educación Popular" Sarmiento habla del carácter esencialmente moral del hombre, manifestando una ideología ética de larga tradición en el pensamiento occidental que entronca con el sistema aristotélico.

"El hombre es un ser moral que menos obra por la reflexión y el sentimiento de la justicia, que por los hábitos contraídos; y estos hábitos vienen desde la más tierna infancia indicando ya el carácter futuro del adulto. La madre educa al niño en los primeros pasos de la vida. Pero sabe la madre medir las consecuencias de los actos, de las pasiones, de los gustos de los hábitos que ella presencia, fomenta o hace nacer?" 46

Según Sarmiento, la escuela puede ser una poderosísima institución social para crear en el individuo los hábitos necesarios que le conviertan en un hombre civil:

"Al hablar de la moral pública debemos señalar otro costado por donde flaquea esta entre nosotros. Lo que las costumbres son a las leyes, es el espíritu público para el gobierno de la sociedad (...) Sucede lo mismo con el espíritu público; él hace lo que la ley no puede hacer, porque es la acción de los sentimientos comunes a una sociedad, manifestándose por actos independientes de la acción gubernativa y el signo más característico de nuestra época, y la 
glorificación de las ideas cristianas son esa multitud de asociaciones de donaciones, de suscripciones, con objeto de promover la mejora intelectual y moral de las clases inferiores, que es lo que distingue a los pueblos más avanzados ${ }^{47}$ [ el subrayado es mío]

Recuerdos de Provincia representa, por excelencia, la metáfora literaria de esta idea, ya que al narrar su autobiografía, Sarmiento ofrece un ejemplo vivo de la transformación de un individuo, él mismo, que logra llegar a ocupar un destacado lugar en la cultura y política Argentina, gracias a su inteligencia y tesón. Allí Sarmiento demuestra su autodisciplina como estudiante, por poner sólo, un ejemplo, cuando menciona su -valga la redundancia- ejemplar asistencia a la escuela.

Algunos críticos han calificado a Sarmiento incluso de egotista. Dice Anderson Imbert (1967) [ver bibliografía] que Faustino D. Sarmiento era popularmente conocido como "Don Yo". Es difícil no darse cuenta de que el escritor, con su estilo sentencioso e inspirado, no evita el atribuirse méritos y explicarnos su vida siempre que le parece necesario. Pero incluso aquí debemos hacer una conexión con la cosmovisón de Sarmiento y lo que trata de hacer a través de su obra. Esta característica de su literatura especialmente en el relato de su biografía, debe entenderse aquí teniendo en cuenta el papel que para sí mismo se adjudica, que en la terminología corriente de nuestros días podríamos denominar como un "role model". Sí, Sarmiento se ve a sí mismo como un modelo para América, para el pueblo que tiene potencialmente la capacidad de

\footnotetext{
${ }^{46}$ Educación Popular, Santiago de Chile, 1848. Tomo XI, p. 244

${ }^{47}$ Educación popular. Santiago de Chile, marzo 8 de 1848 . Tomo XI, p. 33.
} 
llegar a pertenecer- siguiendo los ejemplos adecuados- a una especie de "Atenas de Indias", a la civilidad americana en la utopía Sarmentina.

En efecto, Sarmiento demuestra sentirse orgulloso de sus logros, de sus virtudes, es posible también que las exagere en muchas ocasiones; y todo ello, en última instancia, por esta vocación de maestro, casi de gurú, con fe en su visión sobre el futuro del pueblo argentino. Esta es, sin lugar a dudas, la visión del que quiere ser adalid del progreso del subcontinente. En Recuerdos de Provincias Sarmiento hace hincapié en la formación de su carácter por las virtudes que inspiró su ambiente familiar y principalmente su madre:

"Tal ha sido el hogar doméstico en que me he criado, y es imposible que, a no tener una naturaleza rebelde, no haya dejado en el alma de sus moradores impresiones indelebles de moral, de trabajo y de virtud, tomadas en aquella sublime escuela en que la industria más laboriosa, la moralidad más pura, la dignidad mantenida en medio de la pobreza, la constancia, la resignación, se dividían todas las horas" ${ }^{48}$

Según la línea de pensamiento y de acción que Sarmiento desarrolla, la mejora del continente requiere de una mejora en términos morales, es decir, en términos de hábitos de vida. Para lo cual también el pueblo Argentino debe inspirarse en las personas y en los pueblos que en su opinión tienen un mayor grado de perfección:

${ }^{48}$ Sarmiento, reed. 1962, p. 157. 
"Son vulgarísimos y pasan inapercibidos los primeros síntomas con que las revoluciones sociales que opera la inteligencia humana en los grandes focos de civilización, se extienden por los pueblos de origen común, se insinúan en las ideas y se infiltran en las costumbres. El siglo XVIII había brillado sobre la Francia y minado las antiguas tradiciones, entibiando las creencias y aun suscitando odio y desprecio por las cosas hasta entonces veneradas; sus teorías políticas trastornado los gobiernos, desligado la América de España, y abierto sus colonias a nuevas costumbres y a nuevos hábitos de vida"49

En este mismo sentido Sarmiento ve la necesidad de distanciarse de un legado moralmente corrupto de España. Para Sarmiento la España que conquista el continente es la España Medieval ${ }^{50}$ que trae consigo un elemento de atraso y subdesarrollo. Y no es que la historia de España camine a la zaga de sus hermanas europeas, sino que más bien va a destiempo ${ }^{51}$, como nos menciona en sus cartas cuando viaja por España. Pero fue la España de la cruel Inquisición, de las prácticas supersticiosas, de los saberes esotéricos y la filosofía escolástica la que dominó el continente. Para reeducar a los hijos mestizos de esta herencia será necesario proponer al contrario una educación sin violencia y una educación que se aproveche de los últimos conocimientos que provee la ciencia moderna:

\footnotetext{
${ }^{49}$ Op. cit., p. 158

${ }^{50}$ También Voltaire, a quien Sarmiento cita en varias ocasiones, había sido uno de los intelectuales modernos que atacó con mayor fervor las prácticas supersticiosas de la cultura popular. Muchos de estos pensadores franceses criticaron además las instituciones y el legado moral de la religión católica en el antiguo régimen.

51 ..... [el] destino que parece haber regido en todos tiempos a la España (...) no consiste en andar a remolque de las otras naciones sino a destiempo, dando las 12 cuando todos los relojes marcan las 5, y viceversa. En efecto, cuando todas las naciones de la Europa estaban encorvadas bajo el yugo del despotismo, los españoles tenían en el Aragón sus célebres cortes, donde decían al rey sin quitarse el sombrero « Nosotros, que valemos tanto como vos, y que podemos más que vos, vos instituimos nuestro rey y señor ». Pero cuando la Europa se agitó para obtener un poco de libertad,
} 
"En los pueblos españoles, más que en ningunos otros de los cristianos, han resistido a los consejos de la sana razón prácticas absurdas, cruentas y supersticiosas (...) Fajábanse los niños, como aún es la práctica en Italia y otros países de Europa ricos en preocupaciones y tradiciones atrasadas. El cura Castro, acaso con el Emilio escondido bajo la sotana, enseñaba a las madres la manera de cuidar a los enfermos, las preocupaciones que debían guardar las embarazadas, y a los maridos en conversaciones particulares o en el confesionario, enseñaba los miramientos que con sus compañeras debían tener en situaciones especiales" .52

Sarmiento no sólo desea expandir la escuela para hacerla llegar a todo el pueblo sino que se propone una reforma cualitativa de la misma. Por esto, introduce en los currículos la enseñanza de la Geografía, la historia, las matemáticas. Pero también desea dotar a la escuela con la facultad de formación moral, como garantía para la República de la formación de sus integrantes. Un ejemplo que viene a colación para demostrar cómo esta idea de educación de los hábitos puede ser llevada a cabo por el sistema educativo es el énfasis que Sarmiento hace en la importancia de la gimnasia en el currículo escolar:

"El gaucho, el manolo, el napolitano, el griego dan una puñalada o hunden un estileto, como el caballo da coces, como el toro bravío embiste, por crispación de los nervios, contra el color colorado que lo irrita, por la facilidad de encenderse en cólera, hombre o toro a cada contrariedad. La escuela, la gimnástica, la fila la 
hilera, el compás van disminuyendo las crispaciones, la regla, la repetición de los movimientos vienen amasando el animalito bípedo que cuando llega a la plenitud de su fuerza es un hombre y no un tigre (...)"153

La regeneración del continente es posible para Sarmiento si se eliminan todos los elementos de barbarismo "cancerígeno" que le acucian. La crueldad y superstición de los colonizadores españoles, pero también el servilismo y la ignorancia del indígena y el africano. La literatura de Sarmiento está muchas veces informada de un tipo de ideología que muestra un prejuicio claro en cuanto a la capacidad de organización política de determinados pueblos o razas como hemos discutido en el capítulo anterior.

Sin duda la posición de Martí, como intelectual, derriba muchos de los presupuestos sarmentinos. Ello, sin embargo, no debe sombrear el gran esfuerzo del Sarmiento presidente por hacer llegar la educación a las masas. Para entender mejor esta preocupación acuciante del Sarmiento político hemos buscado en fuentes históricas sobre las que apoyar nuestra discusión y ofrecemos a continuación al lector o lectora los siguientes datos sobre la situación con respecto a la red de escuelas primarias de la Provincia de Salta en la época de Sarmiento, así como los cambios por él introducidos para mejorarla.

Lilia Pérez ${ }^{54}$ describe al presidente Faustino Domingo Sarmiento como el presidente maestro. Siendo educador, para Pérez, Sarmiento privilegió sobre todo la instrucción pública. Según la autora mencionada para llevar a cabo esta labor

\footnotetext{
52 Viajes..., reed. 1962, p. 146.

${ }^{53}$ Sobre la instrucción popular. Tucumán, agosto 12 de 1886 . Tomo XLII, p.378
} 
Sarmiento se apoya como pilares de su reforma política en: la escuela, la inmigración, el orden y el progreso. Efectivamente, Sarmiento fundó millares de escuelas y bibliotecas, nuevas líneas férreas. Explotó la minería, creó un observatorio astronómico, y una Academia de Ciencias en Córdoba. Miles de inmigrantes llegaron durante su gobierno. También creo Sarmiento las primeras Escuelas Normales para mujeres. Introdujo el estudio de la Física y las Matemáticas en la Universidad de Córdoba.

Si nos fijamos en la situación de la educación primaria con que se encuentra Sarmiento vemos lo siguiente:

"En la provincia [Salta] los fondos destinados a la educación alcanzan sólo para educar a un joven de cada 41 analfabetos. El censo de 1867 registra una población de 101143 habitantes en la provincia, de los cuales hay 81057 que no saben leer. Según la misma fuente de información hay 25 escuelas de varones en las que cursan 1356 alumnos y 18 escuelas de niñas con 630 alumnas lo que suma sólo 1986 alumnos"

A principios de 1869 Sarmiento establece por decreto una subvención a la educación primaria de las provincias "habiendo la ley de presupuesto designado para subvencionar la educación primaria en las provincias la cantidad de 100.000 pesos fuertes que se deben repartir entre ellas" y la Rioja recibe además una subvención especial de 7000 pesos a cada una de las provincias.

\footnotetext{
${ }^{54}$ Pérez de Arévalo, Lilia "Algunos aspectos educativos en Salta en la época de Sarmiento » Río de la Plata : Culturas, 1989, vol. 9, pp. 85-91.

${ }^{55}$ Pérez, 1989, p. 86.
} 
Por el artículo 2 de dicho decreto se asignan además 12.000 pesos para comprar libros, textos y otros útiles. El artículo 3 otorga 4.000 pesos en gastos de inspector y visitas a las escuelas.

El 14 de enero de 1869 ocurre otro decreto para la rendición de cuentas de los gastos que garantice que los fondos llegan a la educación, para aquellos que perciban la subvención. También se requiere de un informe sobre el número de escuelas costeadas, total o parcialmente, así como su ubicación, número de alumnos y sueldos de los profesores. Se establece el derecho de los inspectores de visitar las escuelas para comprobar su estado.

Los resultados en Salta sobre el estudio estadístico de la situación de las escuelas fueron deplorables. Existían sólo seis escuelas cinco en edificios municipales y una en una cárcel. Como muebles contaban con algunas bancas y alguna pizarra de madera o lienzo negro. Hay bancas de cardón hechas por el propio preceptor, colocadas sobre adobes. La provincia solicita todo tipo de apoyo. También se solicita la creación de escuelas de niñas, porque muchos pueblos no las poseen. Trece de los departamentos solicitan libros y demás material pedagógico, ya que carecen de ellos. Los únicos ramos de la enseñanza son: lectura, escritura, aritmética y gramática. Sólo hay 5 escuelas de niñas entre todos los departamentos. Se prevé establecer un edificio municipal que sirva para cumplir las funciones de: sesiones del consejo, secretaría, juzgado de paz, cárcel y escuela. Se destinan 1500 pesos para el Colegio de Huérfanas de la ciudad. El gobierno establece también un curso estadístico de las escuelas. 
Además se abrieron aulas nocturnas en el colegio de Salta para la instrucción de los artesanos y proletarios de la ciudad bajo la dirección gratuita de los profesores del establecimiento.

En 1869 por ordenanza municipal se establece la instrucción primaria obligatoria para todos los jóvenes de uno u otro sexo del municipio desde los siete años. La Comisión de Instrucción Pública es la encargada de hacer cumplir la nueva ley.

Estas inversiones, creación y reforma de la instrucción pública para componer una instrucción primaria son parte de la herencia que Sarmiento contribuyó a crear. Porque la democracia del pueblo argentino sería quimérica sin la necesaria instrucción en los conocimientos útiles para el desarrollo y bienestar, para la democracia y la igualdad de la nación. Sarmiento es el maestro-presidente de la Argentina.

" Pero la instrucción primaria es la medida de la civilización de un pueblo. Donde es incompleta, donde yace abandonada, y al alcance de un corto número hay un pueblo semi-bárbaro, sin luces, sin costumbres, sin industria, sin progreso. Lo contrario sucede donde la instrucción primaria llama la atención de todos, y se hace un interés de primer orden, no sólo para el gobierno que lo establece, reglamenta y dirige, sino para cada un padre de familia que vigila el adelanto de sus hijos" 56

${ }^{56}$ Análisis. Advertencia. Ideas Pedagógicas. Santiago de Chile, 22 de agosto de 1842 


\section{CONCLUSIÓN}

La conceptualización de la cultura como civilización en la obra de

Sarmiento está sin lugar a dudas informada por ideas utilitaristas, racionalistas y el afán por emular el desarrollo cultural del continente europeo y los Estados Unidos. Estos modelos chocan sin embargo con una realidad social y culturalmente diferente en Argentina y América Latina. El esquema sarmentino resulta demasiado ingenuo. Al calificar a las culturas indígenas, africanas, la cultura del gaucho, del hombre de pueblo como bárbaras, Sarmiento les otorga un valor sólo potencial. Ve los beneficios del mestizaje en el mulato, pero su falta de profundización sobre la realidad étnica, abalada por teorías en boga en su época, le impide poder vislumbrar una síntesis cultural que incorpore otros valores y otros logros culturales distintos de los de Europa o Estados Unidos.

Sarmiento no sabe cómo resolver el problema de la identidad argentina. Para él un Estado está ligado por una monocultura niveladora y sin embargo el resultado de su política de inmigración no produce una nueva generación de argentinos sino mayor complejidad en la composición cultural del país.

Es importante volver a estudiar el pensamiento de Sarmiento y otros ensayistas latinoamericanos del XIX, para entender el por qué de sus razones, identificar sus aciertos y atisbar los fallos de sus ideas. Sarmiento fue sobre todo un político práctico que entendió la importancia del desarrollo intelectual a través de la creación de escuelas por todo el país, escuelas capaces de acoger a la población entera que puedan proporcionar los conocimientos adecuados para dar a 
hombres y mujeres la oportunidad de mejorar su bienestar o calidad de vida en todos los aspectos : lo físico, lo intelectual, lo moral y emocional.

Sin embargo, su conceptualización de la cultura en términos de un esquema rígido de valores, le impidió otear el desarrollo de una nueva cultura, quizá de una identidad con la apertura suficiente para dar cabida a las razones distintas de las voces de un país multicultural.

El problema del desarrollo unido al problema de la convivencia y el respeto de las culturas son todavía la noticia del día a día en América Latina. Bueno será como sugería Sarmiento ver hasta dónde han llegado o hasta donde no quienes nos han precedido en la creación de una utopía. 


\section{BIBLIOGRAFÍA}

Adams y Searle (ed.) Critical Theory since 1965.

Florida State University Press. Talahassee, 1984.

Alonso, C. « Civilización y barbarie"

Hispania, 1989, vol. 72, Mayo, pp. 256-263

Anderson Imbert, E. Genio y figura de Sarmiento.

Eudeba Editorial universitaria de Buenos Aires, 1967.

Areta Marigo, Gema 'Sarmiento, a vueltas con la barbarie »

Cuadernos Hispanoamericanos, 1996, vol. 551, Mayo, pp. 7-16

Barrenechea, Ana María y Lavandera, Beatriz, R. Domingo Faustino Sarmiento.

Centro Editor de América Latina. Buenos Aires, Argentina, 1967.

Berdiales, G (selección y ordenación) Antología total de Sarmiento.

Editorial culturas argentinas, Buenos Aires, Tomo I y II, 1962.

Brown, Jonathan C. A Socioeconomic History of Argentina, 1776-1860.

Cambridge University Press, 1979.

Cardiel Reyes, R. Los filósofos modernos en la independencia americana.

Universidad Nacional Autónoma de México, 1980.

Congreso Internacional de Literatura Iberoamericana 1969: Toronto. El ensayo y la crítica literaria en Iberoamérica: memoria del XIV Congreso Internacional de Literatura Iberoamericana. Universidad de Toronto, Toronto, Canadá, 24-28 de agosto de 1969. Edición al cuidado de Kurt L. Levy y Keith Ellis, Universidad de Toronto, 1970.

Crowley, F. G. Dominto Faustino Sarmiento.

Twayne Publishers, Inc. New York, 1972.

Cúneo, Dardo Sarmiento y Unamuno.

Editorial Pleamar. Buenos Aires, 1963.

Cywiner, María E. S. De "La civilización como utopía en la mira sarmentina" Río de la Plata: Culturas, 1989, vol. 8, no 4, p. 471

Ferns, H. S. Argentina. New York, Praeger, 1969.

Garrels, Elizabeth "Traducir a América: Sarmiento y el proyecto de una literatura nacional"

Revista de Crítica Literatura Nacional, 1993, vol. 19, no 38, pp. 269-78. 
Goodrich, Diana "Ricardo Rojas, lector de Facundo: Hacia la construcción de la cultura nacional"

Filología, 1986, vol. 21, no 1, pp. 173-181.

Jameson, Fredric The political unconscious. Narrative as a socially symbolic act. Cornell University Press. Ithaca, New York.

Jowett, B. (translator) Aristotele's Politics

The Modern Library. New York, 1943.

Kirchheimer, J. "Los maestros franceses en la enseñanza argentina durante la época de Sarmiento"

Río de la Plata: Culturas, 1989, vol. 8, pp. 99-105.

Levene, R. La cultura histórica y el sentimiento de nacionalidad.

Buenos Aires. Espasa Calpe, 1946.

Lojo, María Rosa "La seducción estética de la barbarie en Facundo"

Estudios Filológicos, 1992, vol. 27, pp. 141-148.

Martínez Echazábal, Lourdes "Positivismo y racismo en el ensayo

latinoamericano"

Cuadernos Americanos, 1988, vol. 2, no 3, pp. 121-129

Mead, R. Breve historia del ensayo hispanoamericano.

México. Ediciones de Andrea, 1956.

Mitre, Antonio "La parábola del espejo: identidad y modernidad en el Facundo de Domingo F. Sarmiento"

Revista de Crítica Literaria Latinoamericana, 1994, vol. 20, no 39, pp. $17-40$.

Pérez deArévalo, Lilia "Algunos aspectos educativos en Salta en la época de Sarmiento"

Río de la Plata: Culturas, 1989, vol. 9, pp. 85-91.

Rovarini, María Rosana "Algunas reflexiones de Sarmiento sobre la colonización española en América: conflicto y armonía de las razas en América 1883-1888"

Río de la Plata: Culturas, 1989, vol. 9, pp. 25-32.

Sarmiento, D. F. Recuerdos de Provincia. Sur. Buenos Aires, 1962.

Sarmiento, D. F ldeas Pedagógicas.

Consejo Nacional de Educación. Buenos Aires, 1938.

Sarmiento, D. F. Viajes. Europa-Africa-América. Selección. 
Editorial universitaria de Buenos Aires, Argentina, 1961.

Sarmiento, D. F. Facundo.

Ediciones Estrada. Buenos Aires, 1940.

Scolie, James R. Argentina. A city and a Nation

Oxford University Press, New York, 1971.

Senkman, L. "Sarmiento y la cuestión étnica"

Río de la Plata: Culturas, 1989, vol. 8, pp. 45-59.

Stavans, Ian (ed) The Oxford Book of Latin American Essays.

Oxford University Press, New York, 1997.

Viñas D. "Sarmiento y su itinerario racista"

Plural: Revista cultural Excelsior, 1981, vol. 11, pp. 19-21.

Weinberg, F. "La dicotomía civilización-barbarie en nuestros primeros románticos"

Río de la Plata: Culturas, 1989, vol. 8, pp. 5-18.

Salazar, D. "Las posiciones de Sarmiento frente al indio"

Revista Iberoamericana, 1984, vol. 50, no 127, pp. 411-427.

Zea, Leopoldo "El proyecto de Sarmiento y su vigencia"

Cuadernos Americanos, 1989, vol. 3, no 13, pp. 85-96. 